\title{
Community-Based Approaches to Tackling Illegal Wildlife Trade-What Works and How Is It Measured?
}

\author{
Olivia Wilson-Holt ${ }^{1 *}$ and Dilys Roe ${ }^{2}$ \\ ${ }^{1}$ Natural Resources Research Group, International Institute for Environment and Development, London, United Kingdom, \\ ${ }^{2}$ International Union for Conservation of Nature (IUCN) Sustainable Use and Livelihoods Specialist Group, International \\ Institute for Environment and Development, London, United Kingdom
}

The illegal wildlife trade (IVT) is a global issue that threatens the conservation of many species of fauna and flora and affects the livelihoods of people who are dependent upon wildlife. By far the most common approach to tackling IWT is to enhance law enforcement, including arming rangers and tougher penalties for perpetrators. Yet, critics of this approach argue that efforts to reduce IWT in source countries are likely to fail without the involvement of local people. However, little is known about the effectiveness of community-based approaches to tackling IWT or how this is being measured. We used information from the www.peoplenotpoaching.org learning platform to analyze over 100 case studies of community-based anti-IWT interventions to understand what proportion have been effective and how this has been measured. We present a typology of frequently reported outcomes, their indicators and means of verification. We show that effectiveness in community-based anti-IWT interventions is measured by a number of indicators and using a variety of verification means. Our findings suggest that conservation practitioners more frequently implement activities to measure conservation outcomes in comparison to livelihood outcomes, which has implications for how we consider if a community-based anti-IWT project has been effective. We recommend that future community-based anti-IWT projects build in more robust monitoring, evaluation and learning activities to measure how livelihood benefits impact local communities given their support is crucial to achieving long-term conservation success.

Keywords: poaching, illegal wildlife trade, local communities, livelihoods, effectiveness

\section{INTRODUCTION}

Illegal wildlife trade (IWT) is a global conservation and development issue that threatens many species of fauna and flora and affects the livelihoods of people who are dependent upon wildlife. Escalating poaching is one of the key drivers of species decline along with habitat loss (Symes et al., 2018), driven by both increasing international demand for wildlife products in consumer countries (UNODC, 2016) and by rising social inequalities in source countries (Moneron et al., 2020; Liew et al., 2021). Premium prices placed on illegally traded wildlife can act as an incentive for people living in areas of high poverty and poor governance to engage in poaching activities (Hübschle and Shearing, 2018). However, although the need to alleviate poverty and address broader socioeconomic inequity as key motivations to engage in IWT is increasingly being recognized, this does not always translate to action on the ground (WWF and IIED, 2019). 
Globally, responses to tackling IWT have primarily relied on strengthening law enforcement, or to a lesser extent on demand reduction campaigns in consumer countries. Analysis by the World Bank estimated that from US $\$ 1.3$ billion invested in combatting IWT between 2010 and 2016, 65\% was allocated to protected area management and law enforcement, compared to just 15\% for community-focused projects (Wright et al., 2016). Similarly, an analysis of government commitments made at international IWT conferences held in London in 2014, Kasane in 2015, and Hanoi in 2016 show that those under the supporting sustainable livelihoods and economic development pillar have made the least progress compared to others (eradicating the market for illegal wildlife products, building effective legal frameworks and strengthening law enforcement) (WWF and IIED, 2019).

The sheer scale of IWT and the involvement of international criminal networks suggests a need for boots on the ground (IIED and IUCN SULi, 2019). Similarly, the perception that IWT is a "crisis," requiring immediate responses to poaching incidents, might help to explain the prominence of law enforcement in antiIWT strategies (IIED and IUCN SULi, 2019; TRAFFIC, 2021). However, top-down approaches, including the use of militarized tactics, often fail to account for underlying motivations behind poaching (Challender and MacMillan, 2014), and can worsen already strained people-park relations and lead to human rights abuses (Duffy et al., 2015; Massé et al., 2017). In ignoring historic costs of conservation, heavy-handed enforcement efforts can both remove incentives for local people to engage in conservation (Cooney et al., 2016; Ngorima et al., 2020) and provide incentives to engage in illegal behavior (Hübschle and Shearing, 2018; Lunstrum and Givá, 2020; Mogomotsi et al., 2020).

Not all law enforcement approaches are problematic, however, and communities can work successfully in partnership with traditional enforcement authorities. This might take several forms, including local people being employed or volunteering as wildlife scouts or guardians, as well as acting as informants (Moreto et al., 2017; Anagnostou et al., 2020). Collaboration between these traditional authorities and local people can be particularly useful in complementing formal ranger patrols with actionable intelligence, especially when this approach is both cognizant of local and cultural circumstances and confidential to avoid any repercussions to informants from within their community (Anagnostou et al., 2020; Atuo et al., 2020). Building mutual trust is key to maintaining strong community-ranger relationships, where rangers can act as a bridge between these two parties and help to generate more positive local attitudes toward conservation (Rizzolo et al., 2021).

Generally, participatory approaches to tackling IWT where communities feel ownership of and can benefit from wildlife are necessary to build local support for conservation (Ngorima et al., 2020; Liew et al., 2021). Engagement might include involving communities in decision making and project design, implementing alternative livelihoods programs or mitigating costs from human-wildlife conflict (HWC). The underlying logic is that if wildlife becomes an asset rather than a cost, local people are more likely to be motivated to protect it (Biggs et al., 2015).
There is no universal approach, however, when it comes to implementing community-based anti-poaching interventions (Roe and Booker, 2019). Instead, solutions should be designed to account for local contexts which vary based on the cultural, political and environmental landscape (Biggs et al., 2016). Taking these factors into consideration as well as understanding how they collectively influence local attitudes and behavior takes time and can lead to doubts amongst anti-IWT project designers and implementers about best practice (Roe and Booker, 2019). An additional problem is the lack of knowledge on the effectiveness of involving Indigenous Peoples and local communities (IPLCs) in efforts to reduce poaching for international IWT. There is similarly limited knowledge on the types of outcomes that are typically achieved in these approaches and how they have been measured.

The People not Poaching: Communities and IWT Learning Platform was designed to address these knowledge gaps. A joint initiative of the International Union for Conservation of Nature Sustainable Use and Livelihoods Specialist Group (IUCN SULi) and the International Institute for Environment and Development (IIED), People not Poaching aims to build the evidence base on the effectiveness of community-based approaches to tackling IWT. By collecting case studies, the purpose of the platform is to understand what does and doesn't work, and why, in these approaches. Although these approaches tend to focus on the poaching of fauna, People not Poaching also includes case studies on tackling illegal trade in both plants and timber species.

In this study we use information reported in case studies on the People not Poaching platform to understand what proportion have been effective in reducing IWT. We look at the type of outcome achieved in interventions reporting effectiveness and categorize these outcomes into a typology. We include information on the indicator used to measure the outcome and the means of verification. We discuss both conservation outcomes and livelihood outcomes and emphasize their equal importance when measuring effectiveness, and therefore defining success, in community-based anti-poaching approaches.

\section{MATERIALS AND METHODS}

The People not Poaching platform can be found online at www.peoplenotpoaching.org and features over 100 case studies of community-based interventions that aim to tackle poaching and IWT. Case studies have been added to the platform since its launch in October 2018 and are drawn from a variety of sources. Most of the initial case studies were identified in Roe and Booker's (2019) synthesis of relevant approaches and lessons for best practice. Case studies have also been submitted by project staff involved in IWT interventions as well as written by the People not Poaching team from publicly available information such as news stories and journal articles. As Roe and Booker (2019) previously found, there is less documented information available on community-based interventions that specifically tackle international IWT than might be expected and we acknowledge that there are likely to be plenty of existing 
and relevant initiatives that are not included on the People not Poaching platform.

The case studies on the platform provide details of the IWT intervention, including location, the target species, the poaching problem, an overview of the approach, its effectiveness and lessons learned. Information on the approach is further split into specific types of community engagement strategy, which are aligned to four pathways developed by Biggs et al. (2016) in a theory of change for community-based actions against IWT. The four pathways are 1. strengthen disincentives for illegal behavior; 2 . increase incentives for wildlife stewardship; 3 . decrease the costs of living with wildlife; 4 . support non-wildlife based livelihood opportunities. An additional strategy, improve education and awareness about conservation and IWT, was also subsequently added to the case studies template on recognition that this was a common approach that was not explicit in the Biggs et al. (2016) theory of change.

Case study submissions are invited to explain whether the intervention has been effective in decreasing pressure on species from IWT (as per the Biggs et al., 2016 theory of change) by summarizing the evidence of both conservation and livelihood outcomes, such as reduced poaching, IWT or deforestation, the protection of habitat or increases in the target species population, or reduced motivation to engage in IWT due to decreased livestock predation or increased household income, for example.

We used this information, which was either provided by project staff or available from public sources, to explore how many case studies reported on the effectiveness of their intervention in decreasing pressure on species from IWT. We categorized interventions as either effective, partially effective or not effective based on the information reported in the case studies and whether or not the case studies had reported decreased pressure on species from IWT. Interventions were categorized as effective if they indicated that they had directly reduced poaching or IWT of the target species, or increased wildlife populations, or that they had indirectly contributed to reduced poaching and IWT by protecting habitats and improving environmental management. Interventions were categorized as partially effective if they indicated that they had reduced poaching or IWT in some areas but not others, or for certain target species but not others. Interventions were categorized as ineffective if they indicated that they had not managed to reduce poaching or IWT of the target species. In addition, interventions that did not provide enough information or where information was vague on the link between the approach and any effect on IWT were categorized as unclear while those with no information at all on effectiveness were recorded as not reported. This included case studies which stated that it was too early at the time of reporting to assess changes. Each case study was categorized by the lead author and reviewed by the second author, with disagreements discussed and reviewed.

We then explored the specific IWT outcomes that were reported in case studies that had been categorized as effective or partially effective in decreasing pressure on species from IWT and explored the indicators typically used to measure these outcomes and the means of verification of those indicators. We categorized the most frequently reported outcomes to produce a typology. We also explored in further detail whether there was any apparent correlation between improved livelihoods and overall effectiveness of the interventions against IWT.

\section{RESULTS}

There were 115 case studies on the People not Poaching platform - most of them studies of ongoing interventions. These were based in 53 different countries across all continents with the exception of Europe and the two poles. The five countries with the most case studies were Indonesia $(n=9)$, Kenya $(n=9)$, Zambia $(n=8)$, Tanzania $(n=7)$ and Cambodia $(n=6)$. The most common regions were East Africa $(n=20)$, South-East Asia $(n=20)$, South America $(n=18)$, and Southern Africa $(n=17)$.

The case studies focused on reducing poaching and IWT of 165 different species of fauna and flora. Although a high proportion of interventions targeted charismatic terrestrial mammals such as African elephants (28\%), big cats (24\%) and African rhinos (10\%), other species at high risk of IWT have also been targeted including various pangolin (11\%) and timber (11\%) species. Aside from timber, a limited number of case studies included a focus on plants (4\%).

Across the case studies, the most common community engagement strategy is to strengthen disincentives for illegal behavior ( $82 \%)$, followed by improving conservation education and awareness (72\%), increasing incentives for wildlife stewardship (68\%), increasing livelihoods that are not related to wildlife $(63 \%)$ and finally decreasing the costs of living with wildlife (36\%) (Figure 1).

A total of 91 (79\%) case studies reported on the effectiveness of their intervention, with 82 case studies (71\%) reported as effective, $6(5 \%)$ as partially effective and $3(3 \%)$ as not effective (Figure 2). There were 5 case studies (4\%) where the information provided on effectiveness was unclear and a further 19 case studies (17\%) that did not report any information or where none could be found from public sources (although a few of these case studies provided details on how they planned to measure effectiveness at a later stage in the project timeline). There did not appear to be any connection between the type of community engagement strategy adopted and the effectiveness of the intervention (based on the number of effective or partially effective case studies associated with each strategy adopted) (Figure 1). Collectively, however, only 50\% $(n=5)$ of interventions that just targeted plants and timber species were reported to be effective, with no information reported for just under a third of these case studies (30\%).

Case studies reported as being effective or partially effective in reducing the pressure on species from IWT based their assessment on a number of different outcomes. These included: reduced poaching (including illegal logging) of target species; increased population numbers of target species; reduced retaliatory killing of target species; increased habitat protection or improved environmental management; improved awareness, attitudes and behavior toward wildlife and conservation; and 


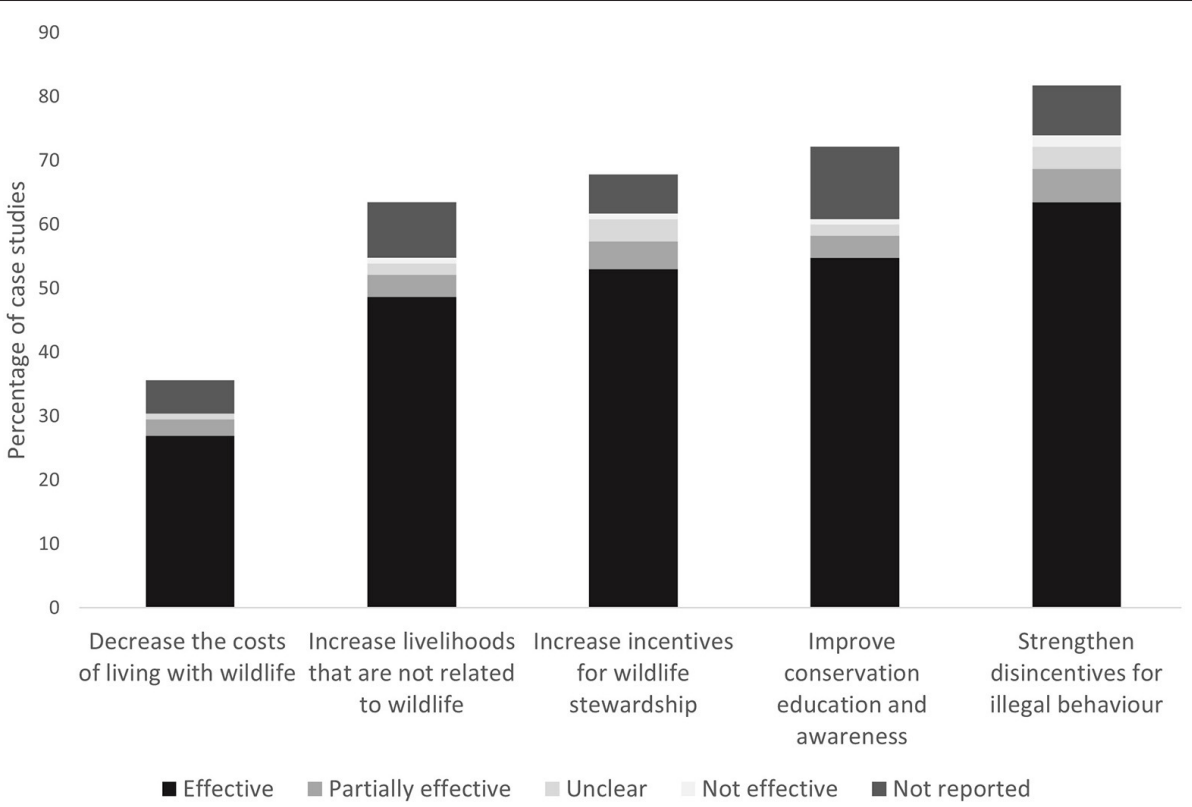

FIGURE 1 | Frequency with which case studies on the People not Poaching platform adopt an approach for engaging communities to decrease pressure on species from IWT including the proportion that are reported to be effective, partially effective or not effective, or where effectiveness was unclear or not reported. The approaches are aligned to pathways developed by Biggs et al. (2016) in a theory of change for community-based actions against wildlife poaching.

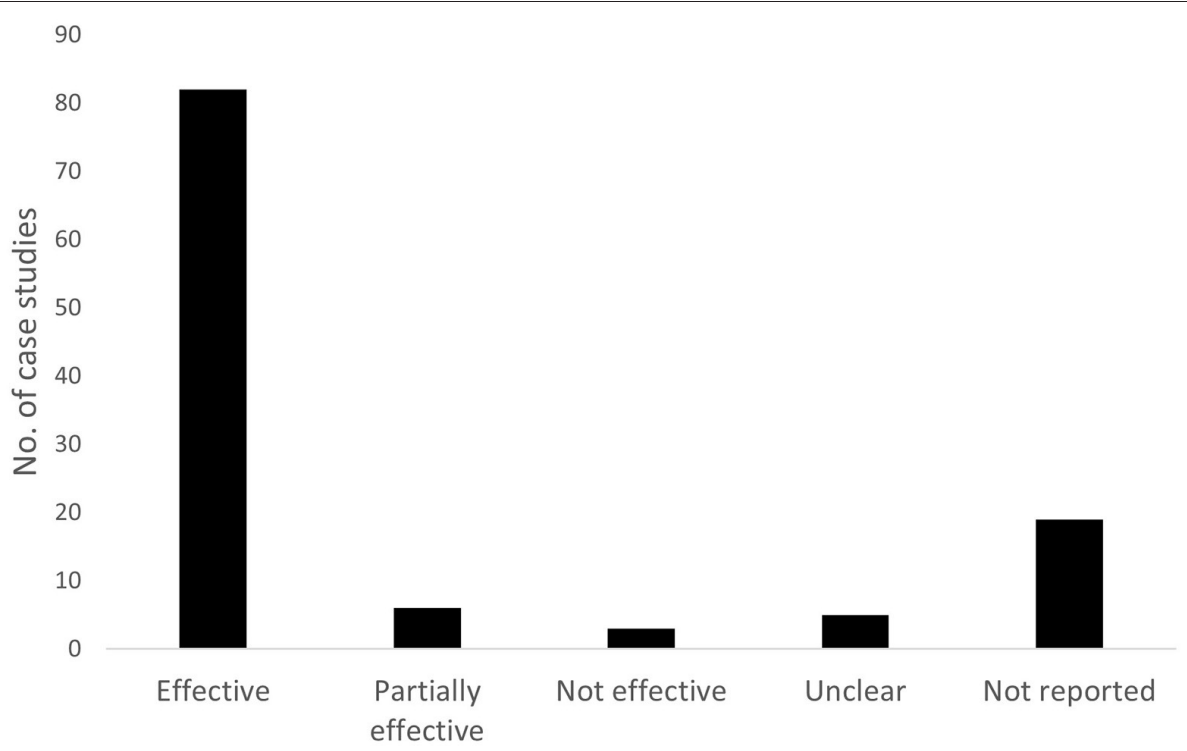

FIGURE 2 | Number of case studies, from a total of 115, reporting that they have been effective, partially effective, or not effective, in reducing IWT and poaching. The graph also includes the number of case studies that were unclear or did not report any information on effectiveness.

reduced involvement in IWT by local people due to improved livelihoods (Figure 3; Table 1).

Across the 88 effective or partially effective interventions, the most frequently reported conservation outcome was a reduction in poaching (including illegal logging), of the target species $(n=72,82 \%)$. Not all case studies provided details on how they had determined there was a reduction in poaching, but for those that did, the most frequently used indicators were the number of incidents detected (e.g., animal carcasses found) $(n=37)$, number of nests protected $(n=9)$, number of seizures (live animals, wildlife parts, firearms, snares) $(n=15)$, number of arrests $(n=15)$, or by changes to community behavior $(n=25)$. For illegal logging, the area of forest protected $(n=7)$, or the number of incidents detected $(n=7)$ were common indicators. 


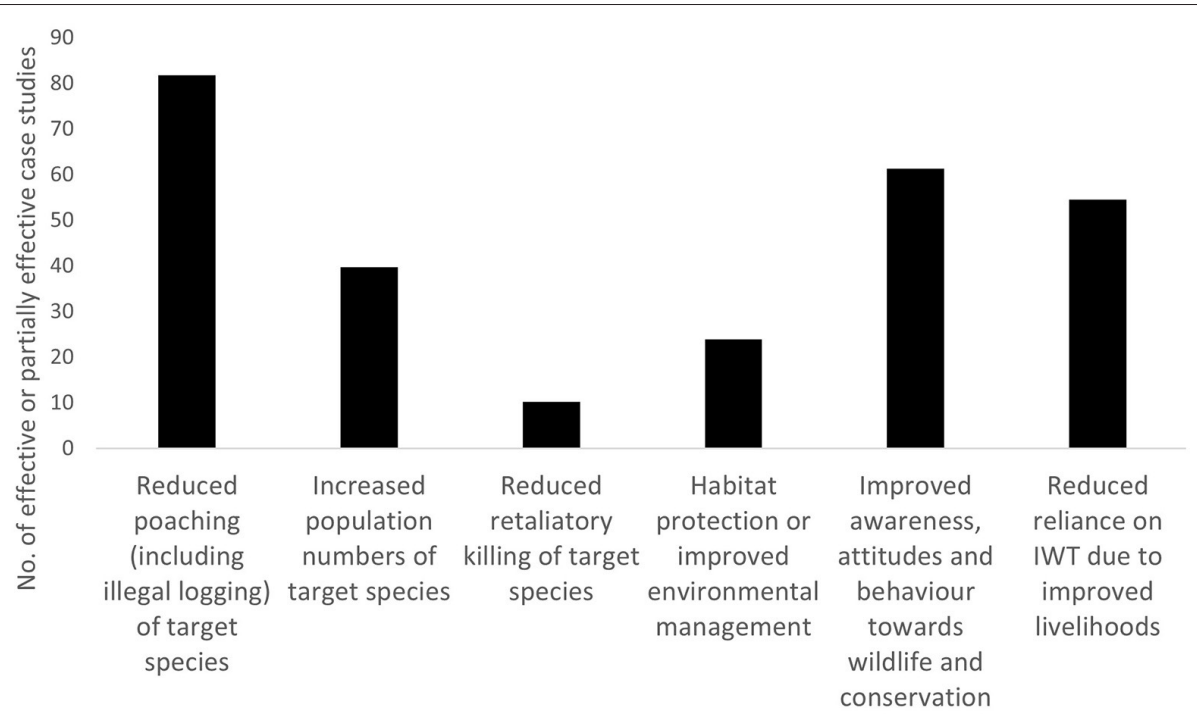

FIGURE 3 | Frequency with which different outcomes were cited as evidence that an intervention is effective or partially effective against IWT.

The means of verification of these indicators (where detailed) included patrol data, satellite imagery and aerial surveillance, alongside anecdotal evidence and observation. Specific methods, such as Monitoring the Illegal Killing of Elephants (MIKE) reports and Global Land Analysis and Discovery (GLAD) forest alerts, were also used, although less often.

Improved awareness, attitudes and/or behavior toward wildlife and conservation were reported for 54 (61\%) of effective or partially effective interventions. Changes to community behavior $(n=28)$, such as observing people voluntarily participating in environmentally friendly practices or informing on wildlife crime, were commonly used to indicate this outcome. For example, in the Democratic Republic of Congo, one case study used the fact that locals were releasing and not capturing live pangolins, as evidence of effectiveness. Some interventions also used the number of people involved in education or awareness raising activities $(n=10)$ and the number of people with positive attitudes toward wildlife and conservation $(n=$ 38) as indicators. For example, in Rwanda follow-up surveys to environmental education activities identified the number of children with positive attitudes toward the environment as well as those stating they would take action to prevent poaching in the future, while in Colombia an evaluation of an education program measured the number of children with increased knowledge of the target species 5 years post-participation. Overall, surveys and observation were the primary means of verification.

Increased population numbers of target species were reported for 35 (40\%) of effective or partially effective interventions. This was most frequently indicated by the number of animals counted $(n=34)$, but also by the number of animals reintroduced to an area $(n=5)$ or the number breeding $(n=4)$. Means of verification were primarily wildlife counts, aerial surveys, satellite tagging, patrols and camera trap images. One case study also measured the number of lizards found alive with microchips that had been inserted $5+$ years previously to show that fewer individuals were being poached.

Increased habitat protection or improved environmental management was reported for 21 (24\%) effective or partially effective interventions. For habitat protection, most case studies identified an increase in the area under protection $(n=13)$ as an indicator of this outcome. Indicators of improved environmental management included development of land-use plans $(n=6)$ and the adoption of sustainable forest management practices $(n=4)$. For example, one case study in Indonesia reported farmers adopting community forest management as evidence of effectiveness.

The final conservation outcome reported as an example of decreased pressure on species from IWT was reduced retaliatory killing of the target species. This was highlighted in nine (10\%) of the interventions categorized as effective or partially effective. This was measured by changes in the number of retaliatory incidents $(n=9)$, which was normally verified by patrol data or anecdotally.

For the three case studies that were categorized as not effective one is an ongoing initiative in Cambodia that is attempting to reduce illegal logging but is struggling against un-cooperative government authorities and illegal activities are still increasing; one was in Madagascar where poaching of the target species spiked just as the project was being implemented and was not brought under control; and one was in Malaysia where a substantial drop in funding led to the closure of communitybased eco-tourism enterprises and a subsequent return to poaching for income.

Case studies that were categorized as unclear $(n=5,4 \%$ of total) either did not report enough information or were too vague to determine effectiveness. For example, two case studies 
TABLE 1 | Typology of frequently reported outcomes from community-based anti-poaching interventions that are either effective or partially effective at reducing IWT and documented on the People not Poaching platform, with information on common indicators and their means of verification.

\begin{tabular}{|c|c|c|}
\hline Outcome & Indicator & Means of verification \\
\hline $\begin{array}{l}\text { Reduced poaching (including illegal } \\
\text { logging) of target species }\end{array}$ & $\begin{array}{l}\text { - Number of dead animals } \\
\text { - Number of nests protected } \\
\text { - Number of seizures (firearms, snares, wildlife products, live } \\
\text { animals) } \\
\text { - Number of arrests } \\
\text { - Area of forest protected } \\
\text { - Changes in community behavior }\end{array}$ & $\begin{array}{l}\text { - Aerial surveillance } \\
\text { - Observation } \\
\text { - Patrols } \\
\text { - Satellite imagery }\end{array}$ \\
\hline $\begin{array}{l}\text { Increased population numbers of target } \\
\text { species }\end{array}$ & $\begin{array}{l}\text { - Number of animals counted } \\
\text { - Number of animals released or reintroduced }\end{array}$ & $\begin{array}{l}\text { - Aerial surveys } \\
\text { - Camera trap images } \\
\text { - Patrols } \\
\text { - Satellite tagging } \\
\text { - Wildlife counts or census }\end{array}$ \\
\hline Reduced retaliatory killing of target species & - Number of retaliatory killings & $\begin{array}{l}\text { - Anecdotal evidence } \\
\text { - Patrols }\end{array}$ \\
\hline $\begin{array}{l}\text { Habitat protection or improved } \\
\text { environmental management }\end{array}$ & $\begin{array}{l}\text { - Area protected } \\
\text { - Changes in community behavior }\end{array}$ & - Observation \\
\hline $\begin{array}{l}\text { Improved awareness, attitudes and } \\
\text { behavior toward wildlife and conservation }\end{array}$ & $\begin{array}{l}\text { - Number of people involved in education or awareness } \\
\text { raising activities } \\
\text { - Number of people with increased environmental knowledge } \\
\text { - Number of people with more positive attitudes toward } \\
\text { wildlife and conservation } \\
\text { - Changes in community behavior }\end{array}$ & $\begin{array}{l}\text { - Anecdotal evidence } \\
\text { - Observation } \\
\text { - Surveys }\end{array}$ \\
\hline $\begin{array}{l}\text { Reduced reliance on IWT due to improved } \\
\text { livelihoods }\end{array}$ & $\begin{array}{l}\text { - Changes in community behavior and attitudes toward } \\
\text { wildlife or toward IWT }\end{array}$ & $\begin{array}{l}\text { - Anecdotal evidence } \\
\text { - Observation }\end{array}$ \\
\hline
\end{tabular}

reported that their results varied in different locations but gave few further details. Another reported that the approach had appeared to reduce poaching but did not explain how or why this was concluded.

\section{Livelihood Improvements as a Pathway to Reduced IWT}

The People not Poaching platform documents community-based interventions to tackling IWT and so it is expected that they would aim to deliver a range of incentives and livelihood benefits for communities as part of the approach. Overall, 48 (55\%) of the case studies that were categorized as effective or partially effective reported a link between improved livelihoods and reduced reliance on poaching. The most frequently reported livelihood benefits were increased income, access to formal education and healthcare, reduced livestock predation and crop raiding, and access to enterprise or business development support. Less common but also mentioned across several case studies include increased food security and employment, improved well-being and participation in decision making, female empowerment, and an instilled sense of pride.

To measure how these benefits contributed to IWT reduction, case studies have primarily used changes in attitudes and behavior as indicators, with evidence collected anecdotally and through observation. For example, anecdotal evidence from an initiative in Rwanda was used to suggest that park-level benefits have increased community buy-in and subsequently reduced poaching. Several other case studies reported that community members have specifically stated their intention to stop poaching having received livelihood benefits as part of the initiative. Overall, the provision of economic incentives, such as income from tourism, trophy hunting or the legal harvest of species, as well as compensation for costs incurred through HWC were reported as the most frequent cause of changes to community behavior or attitudes and consequent declines in IWT. Although less frequently, intangible benefits, such as an instilled sense of pride, were also reported.

Along with the 48 case studies that reported a link between improved livelihoods and reduced involvement in IWT, a further three case studies reported a livelihood benefit, for example increased income and food security. However, these case studies did not indicate whether these benefits had subsequently contributed to decreased IWT and were therefore not considered effective from this perspective. The remaining case studies ( $n=40,45 \%)$ only reported effectiveness from a conservation point of view and did not include any information on livelihood improvements or how these have contributed to an overall effect on IWT.

\section{DISCUSSION}

Despite reducing IWT being a top conservation priority there is very little evidence to understand the effectiveness of community-based approaches to tackling poaching and even less information on how this has been measured. Our study shows that a high proportion of case studies on the People not Poaching platform reported that they have been effective in decreasing pressure on species from IWT citing a 
variety of outcomes to support this. We found, however, little consistency in the indicators used to determine effectiveness and their means of verification. We also found that just over half of effective or partially effective case studies reported a livelihood benefit, but that aside from using anecdotal evidence and observation, there was a lack of information on how the livelihood benefits had contributed to reduced pressure of species from IWT, which is the overall objective of these interventions.

Similar studies with a wider focus on community-based conservation approaches have also found a lack of evidence on the effectiveness of these types of intervention (Brooks et al., 2013; Roe et al., 2015). One problem, demonstrated by our typology, is that there are lots of different ways to indicate success in reducing IWT, ranging from direct impacts to the target species, to indirect impacts such as broader environmental protection and improved awareness of conservation. This is not surprising, given anti-IWT interventions are implemented to respond to local ecological, social, economic and cultural conditions, and are therefore likely to produce a range of effects based on these particular circumstances (Brooks et al., 2013). What our results show, however, is that regardless of the specific context, conservation outcomes such as a reduction in poaching or an increase in population of the target species, are more routinely measured compared to understanding how livelihood benefits contribute to overall project success. This is particularly true when interventions targeted fauna, with a smaller proportion of case studies that just focused on flora reporting effectiveness compared to the proportion of all case studies reporting effectiveness. This could reflect the fact that measuring the impacts of illegal trade in species such as cycads, cacti and orchids is more difficult compared to terrestrial mammals, for example, or because there is a funding and research bias toward tackling IWT in charismatic fauna (Marguiles et al., 2019).

We found that $45 \%$ of all case studies that were reported as effective or partially effective did not report any livelihood benefits. Given these are community-based interventions, we would have expected them to report some kind of benefit to communities in order to reduce their reliance on poaching and subsequently decrease IWT. Local support is important for conservation and so the problem with relying on measures of success that are purely ecological is that it ignores the human dimensions that are needed to make an intervention effective (Nilsson et al., 2016; Mogomotsi et al., 2020). Case studies that were reported to be effective, but that did not measure livelihood contributions as part of their overall evaluation, may therefore risk oversimplifying or overestimating their results (Woodhouse et al., 2015). For example, a case study based in Laos reported their positive findings with caution due to small sample sizes and short study duration, noting that short-term gains to wildlife do not necessarily translate into longer-term impacts. This was the situation for a similar initiative in Malaysia that ultimately did not manage to reduce poaching because in this case the ecotourism enterprise, which was the main source of community income, was not sustainable.
Case studies that did report livelihood benefits frequently highlighted income generation as an important factor in incentivizing communities to stop poaching. Similar results have been found elsewhere to suggest that financial benefits can significantly increase motivations for local people to participate in conservation and vice versa (Mamba et al., 2020; Ngorima et al., 2020). However, given that underlying motivations behind poaching can be diverse and extremely localized (Hübschle and Shearing, 2018; Lunstrum and Givá, 2020; Moneron et al., 2020), it is likely that non-monetary benefits to communities are also important for reducing IWT and the likelihood of ex-poachers reoffending. Our results support this, for example, one case study in Indonesia reported that the pride that comes with being a community ranger is a key reason why many ex-poachers have reformed to become wildlife protectors. Similarly, in their study, Ngorima et al. (2020) found communities agreed that ownership rights and an equal voice in decision-making would improve attitudes toward elephants, thereby underlying the importance of different types of livelihood benefits.

One of the case studies from Venezuela reported that permanent results could only be guaranteed from changes to community attitudes toward wildlife. We found that improved awareness, attitudes and behavior toward wildlife and conservation were reported for $61 \%$ of all case studies that had a positive effect on IWT reduction. As with improved livelihoods, these outcomes more frequently relied on anecdotes and observation rather than using quantifiable evidence to measure effectiveness. Some case studies did report using surveys to measure awareness and attitudes toward wildlife and conservation, but behavioral change, which is an extremely important indicator of human-related threats to wildlife such as poaching (Nilsson et al., 2019; Travers et al., 2019), was consistently reported to have been measured by observation. Nilsson et al. (2016) argue that behavior should be quantitatively measured in conservation evaluations, or at the very least the role of behavior in influencing conservation outcomes should be properly explored. Given unjust social and economic factors are the primary drivers of engagement in wildlife crime, methods to measure the effectiveness of community-based anti-poaching interventions should include those from the social sciences rather than relying solely on the assessment of ecological conditions to indicate success (Bennett, 2016; Gruber et al., 2017).

\section{Implications for Project Designers, Implementers, and Funders}

Our study suggests that community-based anti-poaching interventions are more likely to be considered effective in reducing IWT based on the achievement of positive conservation outcomes rather than positive livelihood outcomes. This could be problematic because motivations to engage in poaching are usually driven by socio-economic inequalities, such as poverty, unemployment and ill-education. An understanding of whether interventions have truly provided adequate incentives to stop people engaging in poaching should therefore be a top priority when evaluating success. This means looking 
beyond simply reporting livelihoods benefits and instead focusing on how these collectively contribute to more positive and longer-term changes to attitudes and behavior toward wildlife, as these changes will ultimately have a large impact on IWT reduction. A starting point would be for donors and funders to recognize that in seeking immediate or headline-grabbing results they risk ignoring the bigger picture of what constitutes success in community-based anti-poaching interventions. We recommend that future project designers and implementers make reporting on and evaluating livelihood outcomes an equal priority to conservation outcomes.

\section{DATA AVAILABILITY STATEMENT}

The data analyzed for this study can be found on the People not Poaching platform, https://www.peoplenotpoaching.org.

\section{REFERENCES}

Anagnostou, M., Mwedde, G., Roe, D., Smith, R. J., Travers, H., and Baker, J. (2020). Ranger perceptions of the role of local communities in providing actionable information on wildlife crime. Conserv. Sci. Pract. 2:e202. doi: $10.1111 / \operatorname{csp} 2.202$

Atuo, F. A., Fu, J., O’Connell, T. J., Agida, J. A., and Agaldo, J. A. (2020). Coupling law enforcement and community-based regulations in support of compliance with biodiversity conservation regulations. Environ. Conserv. 47, 104-112. doi: $10.1017 /$ S0376892920000107

Bennett, N. (2016). Using perceptions as evidence to improve conservation and environmental management. Conserv. Biol. 30, 582-592. doi: $10.1111 /$ cobi.12681

Biggs, D., Cooney, R., Roe, D., Dublin, H., Allan, J. R., Challender, D., et al. (2015). Engaging Local Communities in Tackling Illegal Wildlife Trade. Can a 'Theory of Change' Help? IIED Discussion Paper. Available online at: https://pubs.iied.org/ 14656iied (accessed July 26, 2021).

Biggs, D., Cooney, R., Roe, D., Dublin, H., Allan, J. R., Challender, D., et al. (2016). Developing a theory of change for a community-based response to illegal wildlife trade. Conserv. Biol. 31, 5-12. doi: 10.1111/cobi.12796

Brooks, J., Waylen, K. A., and Borgerhoff Mulder, M. (2013). Assessing community-based conservation projects: a systematic review and multilevel analysis of attitudinal, behavioral, ecological, and economic outcomes. Environ. Evid. 2:2. doi: 10.1186/2047-2382-2-2

Challender, D. W. S., and MacMillan, D. C. (2014). Poaching is more than an enforcement problem. Conserv. Lett. 7, 484-494. doi: 10.1111/conl.12082

Cooney, R., Roe, D., Dublin, H., Phelps, J., Wilkie, D., Keane, A., et al. (2016). From poachers to protectors: engaging local communities in solutions to illegal wildlife trade. Conserv. Lett. 10, 367-374. doi: 10.1111/conl.12294

Duffy, R., St John, F. A. V., Büscher, B., and Brockington, D. (2015). The militarization of anti-poaching: undermining long term goals? Environ. Conserv. 42, 345-348. doi: 10.1017/S0376892915000119

Gruber, J., Mbatu, R., Johns, R., and Dixon, B. (2017). Measuring conservation success beyond the traditional biological criteria: the case of conservation projects in Costa Rica, Mekong Valley, and Cameroon. Nat. Resour. Forum. 42, 19-31. doi: 10.1111/1477-8947.12132

Hübschle, A., and Shearing, C. (2018). Ending Wildlife Trafficking: Local Communities as Change Agents. The Global Initiative Against Transnational Organized Crime. Available online at: https://globalinitiative.net/wpcontent/uploads/2018/08/TGIATOC-Wildlife-Trafficking-Report-WEB4.pdf (accessed July 24, 2021).

IIED and IUCN SULi (2019). Community-Led Approaches to Tackling Illegal Wildlife Trade: Case Studies From Latin America. IIED, London. Available online at: https://pubs.iied.org/17656iied (accessed July 24, 2021).

\section{AUTHOR CONTRIBUTIONS}

OW-H led the analysis and the writing of the manuscript. All authors contributed to and agreed the final version of the paper.

\section{FUNDING}

The People not Poaching platform and this analysis are part of the project LeAP: Learning and Action Platform for Community Engagement Against IWT funded by the UK Government's Illegal Wildlife Trade Challenge Fund (Project Number IWT060).

\section{ACKNOWLEDGMENTS}

We would like to thank everyone that has contributed to a case study on the People not Poaching platform.

Liew, J. H., Kho, Z. Y., Lim, R. B. H., Dingle, C., Bonebrake, T. C., Sung, Y. H., et al. (2021). International socioeconomic inequality drives trade patterns in the global wildlife market. Sci. Adv. 7:19. doi: 10.1126/sciadv.ab f7679

Lunstrum, E., and Givá, N. (2020). What drives commercial poaching? From poverty to economic inequality. Biol. Conserv. 245:108505. doi: 10.1016/j.biocon.2020.108505

Mamba, H. A., Randhir, T. O., and Fuller, T. K. (2020). Community attitudes and perceptions concerning rhinoceros poaching and conservation: a case study in eSwatini. Afr. J. Wildlife Res. 50:1. doi: 10.3957/056.050. 0001

Marguiles, J. D., Bullough, L.-A., Hinsley, A., Ingram, D. J., Cowell, C., Goettsch, B., et al. (2019). Illegal wildlife trade and the persistence of "plant blindness". Plants People Planet. 1, 173-182. doi: 10.1002/ppp3.10053

Massé, F., Gardiner, A., Lubilo, R., and Themba, M. N. (2017). Inclusive anti-poaching? Exploring the potential and challenges of community-based anti-poaching. South Afr. Crime Q. 60:19-27. doi: 10.17159/2413-3108/2017/v0n60a1732

Mogomotsi, P. K., Mogomotsi, G. E. J., Dipogiso, K., Phonchi-Tshekiso, N. D., Stone, L. S., and Badimo, D. (2020). An analysis of communities' attitudes toward wildlife and implications for wildlife sustainability. Trop. Conserv. Sci. 13:1940082920915603. doi: 10.1177/1940082920915603

Moneron, S., Armstrong, N., and Newton, D. (2020). The People Beyond the Poaching. TRAFFIC, UK. Available online at: https://www.traffic.org/site/ assets/files/13126/web-beyond-the-poaching-offender-survey.pdf (accessed July 25, 2021).

Moreto, W. D., Brunson, R. K., and Braga, A. A. (2017). 'Anything we do, we have to include the communities': law enforcement rangers' attitudes towards and experiences of community-ranger relations in wildlife protected areas in Uganda. Br. J. Criminol. 57, 924-944. doi: 10.1093/bjc/azw032

Ngorima, A., Brown, A., Masunungure, C., and Biggs, D. (2020). Local community benefits from elephants: can willingness to support anti-poaching efforts be strengthened? Conserv. Sci. Pract. 2:e303. doi: 10.1111/csp2.303

Nilsson, D., Baxter, G., Butler, J. R. A., and McAlpine, C. A. (2016). How do community-based conservation programs in developing countries change human behaviour? A realist synthesis. Biol. Conserv. 200, 93-103. doi: 10.1016/j.biocon.2016.05.020

Nilsson, D., Fielding, K., and Dean, A. J. (2019). Achieving conservation impact by shifting focus from human attitudes to behaviors. Conserv. Biol. 34, 93-102. doi: $10.1111 /$ cobi.13363

Rizzolo, J. B., Gore, M. L., Long, B., Trung, C. T., Kempinski, J., Rawson, B., et al. (2021). Protected area rangers as cultural brokers? Implications for wildlife crime prevention in Viet Nam. Front. Conserv. Sci. 2:698731. doi: $10.3389 /$ fcosc.2021.698731 
Roe, D., and Booker, F. (2019). Engaging local communities in tackling illegal wildlife trade: a synthesis of approaches and lessons for best practice. Conserv. Sci. Pract. 1:e26. doi: 10.1111/csp2.26

Roe, D., Booker, F., Day, M., Zhou, W., Allebone-Webb, S., Hill, N. A. O., et al. (2015). Are alternative livelihood projects effective at reducing local threats to specified elements of biodiversity and/or improving or maintaining the conservation status of those elements? Environ. Evid. 4. doi: 10.1186/s13750-0150048-1

Symes, W. S., Edwards, D. P., Miettinen, J., Rheindt, F. E., and Carrasco, L. R. (2018). Combined impacts of deforestation and wildlife trade on tropical biodiversity are severely underestimated. Nat. Commun. 9:4052. doi: 10.1038/s41467-018-0 $6579-2$

TRAFFIC (2021). The Conservation Crisis of Our Time. Available online at: https:// www.traffic.org/about-us/illegal-wildlife-trade/ (accessed July 26, 2021).

Travers, H., Archer, L. J., Mwedde, G., Roe, D., Baker, J., Plumptre, A. J., et al. (2019). Understanding complex drivers of wildlife crime to design effective conservation interventions. Conserv. Biol. 33, 1296-1306. doi: $10.1111 /$ cobi.13330

UNODC (2016). World Wildlife Crime Report: Trafficking in Protected Species. Available online at: https://apo.org.au/sites/default/files/resource-files/201605/apo-nid65084.pdf (accessed July 25, 2021).

Woodhouse, E., Homewood, K., Beauchamp, E., Clements, T., McCabe, J., Wilkie, D., et al. (2015). Guiding principles for evaluating the impacts of conservation interventions on human well-being. Philos. Trans. R. Soc. B 370:1681. doi: 10.1098/rstb.201 5.0103
Wright, E. M., Bhammar, H., Gonzalez Velosa, A. M., and Sobrevila, C. (2016). Analysis of International Funding to Tackle Illegal Wildlife Trade. Washington DC: World Bank Group. Available online at: https://documents.worldbank.org/ en/publication/documents-reports/documentdetail/695451479221164739/ analysis-of-international-funding-to-tackle-illegal-wildlife-trade (accessed July 25, 2021).

WWF and IIED (2019). More Than Words: Are Commitments to Tackle Illegal Wildlife Trade Being Met? Godalming: WWF-UK. Available online at: https:// www.wwf.org.uk/sites/default/files/2019-08/WWF_IWT_Report_v8.pdf (accessed July 25, 2021).

Conflict of Interest: The authors declare that the research was conducted in the absence of any commercial or financial relationships that could be construed as a potential conflict of interest.

Publisher's Note: All claims expressed in this article are solely those of the authors and do not necessarily represent those of their affiliated organizations, or those of the publisher, the editors and the reviewers. Any product that may be evaluated in this article, or claim that may be made by its manufacturer, is not guaranteed or endorsed by the publisher.

Copyright (๑) 2021 Wilson-Holt and Roe. This is an open-access article distributed under the terms of the Creative Commons Attribution License (CC BY). The use, distribution or reproduction in other forums is permitted, provided the original author(s) and the copyright owner(s) are credited and that the original publication in this journal is cited, in accordance with accepted academic practice. No use, distribution or reproduction is permitted which does not comply with these terms. 